\title{
LA MANDRÁGORA EN CHILE: \\ PROFECÍAS POÉTICAS Y REVELACIONES DEL GÉNERO NEGRO
}

\author{
POR \\ JuLIO E. NORIEGA \\ Indiana University
}

Mandrágora irrumpe oficialmente en la literatura chilena en $1938,{ }^{1}$ como un eco tardío del surrealismo francés. ${ }^{2}$ Irrumpe por tres vías culturales de acción: la editorial, la revista y el grupo.

La Editorial Mandrágora, constituida en 1939, cesó de publicar en 1973, después de haber difundido, en forma exclusiva a lo largo de los 33 años, la obra de los escritores vinculados al movimiento del mismo nombre. Enrique Gómez-Correa -uno de los más asiduos mandragoristas - es quien la pudo mantener hasta esta fecha, convirtiéndola en un sello editor de sus propios libros. Obviamente, el mayor mérito de Mandrágora como editorial es haber lanzado a circulación, en su condición de entidad cultural sin fines de lucro, lo mejor de la producción literaria surrealista en Chile.

La revista Mandrágora, para los conocedores del vanguardismo en el universo latinoamericano, no sólo fue el vocero surrealista de mayor duración, ${ }^{3}$ sino que con sus siete cuadernillos, cuyas páginas envuelven un lustro de existencia —de 1938 a $1943-$ constituye "una antología del surrealismo internacional." (Baciu 1974: 89). Como tal, recoge manifiestos, poemas y reseñas de libros. En su aparición, atraviesa, igual que toda revista con algunos años de vida, por dos momentos muy marcados. De 1938 a 1941, en

\footnotetext{
' Año que marca el "bautismo" o la "fundación" de Mandrágora según declaración de sus propios gestores, Gómez-Correa y Braulio Arenas (Baciu 1979: 25, 35). Todas la citas que remitan a este volumen han sido tomadas de las respuestas que ambos escritores dieron a las preguntas formuladas por Stefan Baciu.

${ }^{2}$ Recuérdese que el surrealismo se inicia en 1924 con El manifiesto de Breton y que Vallejo en 1930 escribía que "La última escuela de mayor cartel, el superrealismo, acaba de morir oficialmente" (Vallejo 1930: 45). No obstante, el surrealismo chileno - movimiento de mayor representatividad surrealista en Latinoamérica - ha llamado la atención de todos los críticos y, a la vez, ha motivado polémicos e interesantes estudios que, si aún no han llegado a establecer las bases necesarias para una mejor comprensión del fenómeno, por lo menos han iniciado una revisión seria y rigurosa de la presencia surrealista en la literatura chilena. Entre ellos, están los trabajos de Stefan Baciu (1974: 86-98), Marta Contreras (1985), Cedomil Goic (1977), Enrique Lihn (1970), Tomás Rey (1972), Francisco Santana (1976: 241-254) y Jason Wilson (1970).

${ }^{3}$ Que, la primera revista surrealista en Latinoamérica, apareció en 1928, en Buenos Aires, y desapareció en 1930.
} 
que a nombre de todo el grupo salen a luz sus desiguales seis números, ${ }^{4}$ sirve de trinchera política, bajo la sombra de Huidobro, para atacar a determinados escritores - Neruda en especial- y difunde, con enfermizo afán de adscribirse en la tradición literaria europea, los postulados surrealistas. En cambio, el último número (7), que aparece en 1943, rompiendo un largo período de agonía al puro estilo surrealista, ${ }^{5}$ más que "testimonios de un poeta negro"6 es un balance a modo de testamento, cuya confesión consiste en señalar traidores y fieles a la doctrina de Mandrágora y en transmitir la última voluntad de que los primeros, los "pecadores", sean expulsados del reino de la poesía negra. De cualquier modo, en estos días han surgido grandes expectativas por conocer la revista Mandrágora. Los críticos, convencidos de lo imposible que es estudiar la literatura surrealista sin sus revistas, la están rescatando y difundiendo cada vez más. En varios libros y artículos aparecen, aunque breves, sagaces incursiones sobre los autores mandragóricos y/o se reúnen fragmentos de poesías publicadas en la revista. ${ }^{7}$ No obstante, lo que más necesitamos es un estudio riguroso, capaz de evaluar los alcances y el papel que le tocó desempeñar a Mandrágora en el proceso histórico de la literatura chilena.

La vigencia del grupo responsable de estas dos instituciones culturales se remonta, en palabras de Gómez-Correa, a un período "prefundacional", que cronológicamente corresponde a los años 1932-1938, y se proyecta en forma organizada hasta 1943. Estos años son claves en la vida institucional de Mandrágora. Si el grupo nace en 1932, en Talca, ciudad volcánica situada en el corazón de Chile, es recién en 1938 cuando se legitima públicamente en Santiago, con la lectura de sus manifiestos en un recital poético ${ }^{8}$ y con la aparición de la revista Mandrágora. ${ }^{9}$ Mientras que en 1943, el último número de esta revista anunciaba ya la inminente disolución de la organización ${ }^{10}$ y Leitmotiv, ${ }^{11}$ revista fundada por Braulio Arenas, se retiraba del público con un número doble (2-3), todavía en 1948, en la "Galería Dédalo, de Santiago de Chile, [se] presentó una exposición en la cual figuraron los más destacados representantes del surrealismo nacional e internacional" (Baciu

\footnotetext{
${ }^{4}$ Los números 5 y 6 ya entran en decadencia.

${ }^{5}$ Por sus metas y métodos los surrealistas "no pasan de gérmenes patológicos, condenados a devorarse a sí mismo" (Vallejo 1930: 46).

${ }^{6}$ Así se titula el solitario artículo, el de Gómez-Correa (1943), al que se reduce el número 7 de la revista. En verdad, desde un punto de vista más documental, el libro El AGC de la Mandrágora, publicado por Arenas, Gómez-Correa y Cáceres (1957), es el que merece ser reconocido como testamento. Éste ofrece, al margen de textos poéticos y fragmentos de artículos, una bio-bibliografía de autores y un vocabulario de Mandrágora.

${ }^{7}$ Véase la bibliografia básica que se acompaña al final de este trabajo.

${ }^{8}$ El recital se llevó a cabo en el auditorium de la Universidad de Chile el 12 de julio de 1938, donde Braulio Arenas, Teófilo Cid y Enrique Gómez-Correa participaron con la lectura de sus "poemas y textos".

${ }^{9} \mathrm{El}$ primer número se publicó en diciembre de 1938.

${ }^{10}$ Gómez-Correa, único responsable de este número, señala sus discrepancias con Braulio Arenas y lo hace culpable de la dispersión de los miembros de Mandrágora: "Lejos estoy ... Lejos de ese Arenas causante de la dispersión de las mejores posibilidades del grupo Mandrágora" (GómezCorrea, 1943: 12).

${ }^{11}$ Aparecen como colaboradores de esta revista casi todos los mandragoristas, inclusive GómezCorrea.
} 
1974: 91). Pero, la verdadera importancia de esos años no radica tanto en la transición de una etapa "prefundacional", de gestación, a otra "fundacional", de realización, que experimenta el grupo hasta el momento de su dispersión definitiva; por el contrario, hay que buscarla en el proceso cultural de la sociedad chilena. En el contexto internacional, Chile recibió el impacto de la descomposición occidental burguesa de entreguerras y del auge político stalinista, franquista y nazi-fascista; y en el plano nacional, la migración juvenil de provincias hacia la capital y el acceso a la educación hicieron posible que la clase media jugara un rol intelectual muy dinámico. Creo que el encuentro entre Enrique Gómez-Correa, Braulio Arenas y Teófilo Cid, como la posterior preocupación política y poética que los unió, aunque los mismos protagonistas recurran al "azar" en sus explicaciones, ${ }^{12}$ refleja un poco ese momento histórico de reformulaciones. No es obra del "azar" el origen provinciano de los tres estudiantes fundadores ${ }^{13} \mathrm{ni}$ el violento final de algunos militantes del grupo. ${ }^{14}$ Es más, para complicar el asunto, el programa poético y político que introdujeron, la actitud personal que como sujetos asumieron y el afán que demostraron por convertir los escenarios públicos en cenáculos, sus revistas en biblias y sus manifiestos en sermones dan cuenta, en Mandrágora, de una compleja operación ideológica.

Por lo general, la crítica ha visto en Mandrágora un proyecto innovador muy poco original. La apreciación no sólo es verdadera, sino obvia, ya que los mismos mandragoristas así se identificaron abiertamente. En particular, me interesa recoger de ese corpus casi homogéneo dos ideas lanzadas tangencialmente en dos distintos artículos. La primera viene de Enrique Lihn: "del surrealismo tardío, lo menos que podría decirse, pasando por alto sus incongruencias, es que nos parece anticuado y sofisticado." (Lihn 1970: 92). ${ }^{15} \mathrm{La}$ segunda pertenece a Marta Contreras, quien, al establecer dos tipos de discurso en Mandrágora, usa, para el segundo, el término "programático y profético" 16 "discurso de saber": "El discurso mandrágora es un discurso de saber. La posesión del saber posibilita una acción que se realiza en el presente pero cuyos resultados se verán en el futuro" (Contreras 1985: 32). En vista de que ambos autores, con sus insinuaciones, abren un

\footnotetext{
${ }^{12}$ Enrique Gómez-Correa cree que "El azar ha jugado en la vida del grupo Mandrágora un papel fundamental desde su fundación, mejor diría desde su prefundación. Fue el azar el que hizo que sus tres fundadores nos reuniéramos durante los años 1932 y 1933 en Talca" (Baciu 1979: 25).

13 "Braulio Arenas venía de La Serena, vale decir del Norte Chico, cuya región se caracteriza por sus minas y los buscadores de metales. Teófilo Cid llegaba de Temuco, o sea desde la parte sur del país, bien característica por su frondosa vegetación y por sus lluvias. Y yo, [Gómez-Correa] que era de Talca, que sobresale por sus temblores y terremotos y sus abundantes viñedos. Así Arenas aportaba los metales, Cid el elemento vegetal y el agua y yo el alcohol y la violencia telúrica. ¡Misterio, misterio alquímico, del que saldría la Mandrágora!" (Baciu 1979: 25).

14 Jorge Cáceres se suicidó en 1949; Teófilo Cid murió en 1964 con la fama de poeta maldito, "de roto y de aristócrata" a la vez; y Carlos de Rokha, hijo del poeta Pablo de Rokha, se mató lanzándose de un segundo piso.

${ }^{15}$ Subrayo la palabra "anticuado". Sobre el tema de lo anticuados que resultan en Europa los aportes vanguardistas en Latinoamérica, ver el artículo "Contra el secreto profesional" de César Vallejo (1986: 195-197), publicado originalmente en 1927.

${ }^{16}$ Vuelvo a poner énfasis en la palabra que me parece clave.
} 
camino aún desconocido y provocan la gran tentación de recorrerlo, intento seguir explorando con el único objetivo de $\operatorname{probar}^{17}$ que el terror - principio fundamental en la poética negra- la constitucion del sujeto y su forma de ejercer el discurso son tan viejos como las mismas ideologías que los reproducen: la cristiana y la capitalista.

\section{LAS SECRETAS REVELACIONES DEL "GÉNERO NEGRO"}

Existe un mal que desde hace siglos afecta a casi la totalidad de los estudios literarios: es el de los géneros. A causa de esta epidemia, entre otras cosas, la creación literaria aparece fragmentada ante la crítica que tampoco se salva de dicho mal. Pocas veces o quizás nunca se presta atención, por ejemplo, a los vasos comunicantes entre la narrativa y la poesía. Los postulados poéticos que proclamaron los mandragoristas constituyen un buen motivo para vincular ambas formas de creación. Su apología al crimen, el terror y la violencia, tiene algo que ver con el "género negro" que, promovido en los años 20 por los tough writers norteamericanos (Hammett, Chandler y otros), explotó los mismos instintos para crear novelas de gran impacto y popularidad en Estados Unidos y en Latinoamérica. ${ }^{18}$

Desde una primera aproximación, tanto el "género negro" como la poética negra en Chile, denuncian un antecedente común. La moderna novela negra abraza la paternidad de Edgar Allan Poe, clásico de "las tres primeras historias del crimen". 19 Igualmente, los poetas chilenos ven en él a un maestro, excelente narrador de historias misteriosas y maravillosas, "de la novela del terror, de la poesía del terror." (Gómez-Correa 1939: 6). Éste es el Poe - y no el poeta- el único americano ${ }^{20}$ a quien estos surrealistas "de segunda mano"21 buscaron imitar en poesía con la misma intensidad que a los europeos Lautréamont, Sade y Breton.

Otra perspectiva de acercamiento un poco más detenida que la anterior permite, tanto en el género negro como en la poesía negra chilena, establecer ciertas similitudes. Lo cual

\footnotetext{
${ }^{17}$ Para este propósito, me serviré únicamente de los textos teóricos o manifiestos publicados en varios números (1-4 y 7) de la revista Mandrágora y de las respuestas que Braulio Arenas y Enrique Gómez-Correa dieron a las preguntas formuladas por Baciu (1979). De modo que todo cuanto se diga en las siguientes líneas es aplicable única y exclusivamente a ellos, aunque alguna de las ideas tuviera validez para el estudio del resto de las obras, especialmente las de creación.

18 "Esa realidad descrita con violencia y despiadadamente llegó a América Latina en forma de colecciones populares" (Giardinelli 1984: 146).

${ }^{19}$ Así son considerados por Mempo Giardinelli (1984: 21) "Los asesinatos de la calle Morgue" (1841), "El misterio de Marie Roget" (1842) y "La carta robada" (1849).

${ }^{20}$ Despreciaron a todos los demás: "Antes de la aparición de Mandrágora la poesía está dominada por un verbalismo desenfrenado que encuentra su cumbre en el Loro de Nicaragua, me refiero a Rubén Darío ... Una [sic] solo nombre, uno solo, Edgar Allan Poe, es capaz de sostenerse en su propia grandeza: lo demás podredumbre intrascendente, Whitman aun." (Gómez-Correa 1943: 5). Si en un primer momento mostraron simpatía por Huidobro, al último, desilusionados, también lo subestimaron. En el siguiente párrafo del mismo artículo se lee: "Vicente Huidobro, 'el sembrador de escarcha', intenta en vano resolver problemas estéticos de manera simplista. Ataca el automatismo, proclamado por los surrealistas, confundiendo en forma grosera las distinciones elementales entre la actividad poética, la poesía pura y las concreciones y cristalizaciones poéticas (poema)".

${ }^{21}$ Peyorativo usado por Nicanor Parra.
} 
no significa la negación de sus diferencias ni, mucho menos, la anulación de sus oposiciones. Dejando de lado estos dos últimos niveles de comparación, cuyo cotejo o análisis es competencia exclusiva de un estudio comparativo, y limitándome a algunas de sus semejanzas, puedo afirmar categóricamente que las características que en conjunto poseen, así como las condiciones que demandan para su realización (producción, recepción), remiten en lo fundamental a una misma y única preocupación artística.

La novela negra moderna, a diferencia de la novela policial clásica de la cual proviene, se caracteriza por ser "dura, de acción y suspenso; violenta y ácida antes que deductiva; vital antes que intelectual" (Giardinelli 1984: 144). Asimismo, no bastan el anarquismo y el seudomarxismo inherentes a todo movimiento surrealista para explicar la alta dosis de agresividad y violencia que los manifiestos inyectaron contra ese momento cultural en Santiago; tampoco son suficientes la apelación al inconsciente y a la exploración de lo desconocido, vistos por los surrealistas como motores de cambio en la humanidad, para entender que los textos teóricos, planteando la "libertad absoluta de todos los instintos", le rindieran tributo a la acción realizada bajo el imperio de la cólera y, sobre todo, incitaran a cometer actos terribles, tales como el crimen, el masoquismo, el suicidio y el incesto. Entonces, no hay razón para aislar lo negro en la narrativa de lo otro en la poesía, no menos negro aunque en teoría. Por lo menos, el nombre de "poesía negra" con que los mandragoristas se identificaron remite, sin duda alguna, a la tradición literaria policial.

En cuanto a las condiciones de su realización, la novela y la poesía negras son el producto del crimen. Se generan y se proyectan como literatura sobre la base de una determinada función del crimen. Sin esta institucionalización no pueden existir. El crimen es la razón de ser de lo negro y también, su recurso para producir, mediante el "suspense", ${ }^{22}$ ansiedad y pánico en el lector. Por eso, si los poetas negros proclaman que "El crimen precisamente termina donde empieza la poesía" (Gómez-Correa 1938: [8]), los novelistas negros retoman la muerte y el crimen, debilitados por la primacía del misterio frente al "suspense" en la narrativa policial, y los revitalizan hasta convertirlos en "sujetos literarios" (Giardinelli 1984: 144). Y si éstos persiguen provocar con el miedo ansiedad en el lector, aquéllos defienden "la validez del terror como sentido poético" porque "permite vivir en pánico, es decir vivir alertas, vivir despiertos" (Arenas 1938: [3]). Así, el principio constitutivo y el fin supremo del arte negro, tanto en novela como en poesía, abren un solo cauce de punta a punta.

Llevando a ultranza el postulado de la teoría del crimen como productor de literatura en la estructura de toda sociedad burguesa, ${ }^{23}$ la poética negra se inscribe dentro de los

\footnotetext{
${ }^{22}$ Según Nana Badenberg, Alexander Honold y Susanne Hortsmann "Los elementos narrativos de la novela policial están subordinados a la meta principal ... de producir una tensión dramática que, con el término inglés, se define como suspense. Casi en toda la literatura policial este suspense está producido por medio de un incidente mortal: el asesinato es una condición indispensable" (1989: 279-280).

${ }^{23}$ Según Carlos Marx "El filósofo produce ideas, el poeta produce poemas, el cura produce sermones así como el catedrático manuales, etc. Un criminal produce crímenes. Si consideramos más detenidamente la conexión de esta última rama productiva con el todo de la sociedad, hay entonces que sacudirse de muchos prejuicios. El criminal no sólo produce el crimen mismo, sino las leyes sobre los crímenes y, por eso también, al catedrático criminalista con sus conferencias sobre la
} 
marcos de la tradición occidental que, en general, se construye y se explica a partir del crimen (Giardinelli 1984: 27). Sin embargo, el problema no está precisamente en la adscripción que además fue expresa, sino en lo paradójico que tienen los manifiestos, inspirados en principios éticos tradicionales, pero cuya letra de espíritu viejo habla de cambio y revolución, de anticapitalismo y anticristianismo.

\section{LAS NEGRAS PROFECIAAS DE TRES POETAS-PROFETAS}

A los tres fundadores de Mandrágora-Braulio Arenas, Jorge Cáceres y Enrique Gómez-Correa - Winett de Rokha, esposa del poeta chileno Pablo de Rokha, "los llamaba cariñosamente 'los 3 Mosqueteros"' (Baciu 1979: 23). Hoy, después de seguir a través del papel el rastro de sus vidas y el eco de sus voces, puede que también tenga sentido rescatar su imagen de poetas videntes: de tres profetas que predicaron la mística de la Mandrágora.

Los tres poetas llevaron una vida de profetas e inclusive dos de ellos - Cáceres y Arenas-murieron como tales. Fieles o traidores, seguidores o desertores, en algún instante de sus vidas se entregaron por completo a la poesía negra y buscaron revelar la mística de Mandrágora. Enrique Gómez-Correa, el más consecuente de los integrantes, es conocido como el poeta "de lo negro, de la furia, de la noche y de la carcajada trágica [sic] delante del mundo" (Baciu 1974: 93); también se ha destacado por sus estudios teóricos orientados a establecer los lineamientos o principios que rigen la poética negra; y es quien, no hace mucho, envuelto de pies a cabeza en una túnica blanca, ha vaticinado que hay un "Libro Secreto' que transmitirá, más bien a través de la tradición oral, la gran historia o la alucinante leyenda de la Mandrágora" (Baciu 1979: 31). Braulio Arenas, acusado de ser el Judas por haber propiciado la dispersión del grupo, fue un hombre que, renunciando a todo, ${ }^{24}$ vivió para la poesía, y que murió escribiendo "en su lecho de enfermo un poema en que "narraba su propia muerte'. Lo grabó en cassette y al escucharlo, no pudimos ocultar nuestra emoción. Un profundo sentido místico emanaba de su contenido" (Lastra 1988: 151). Y Jorge Cáceres, genio precoz, "unión de talentos y vocaciones que sólo una realización perfecta o la muerte eran capaces de truncar" (Baciu 1974: 94), se suicidó en su departameno de Santiago de Chile, en 1949, escasamente a los 26 años. No obstante, si el horizonte se amplía al resto de los mandragoristas no fundadores, tan legítimos como los otros, la lista se torna también trágica. Pueden servir de ejemplo los casos de Carlos de Rokha y de Teófilo Cid:

Carlos de Rokha, extraordinario poeta, hijo del poeta Pablo de Rokha, vivió y murió deslumbrado por el fuego de la Mandrágora. En una ocasión él se lanzó de un segundo

criminalística y, además, el imprescindible manual de criminalística, lanzado al mercado como mercancía. $\mathrm{Y}$ de esto resulta un crecimiento de la riqueza nacional ... El criminal produce una impresión, en parte moralista, en parte trágica, según el caso, y así presta un servicio al público, movilizando sus sentimientos éticos y estéticos. El produce pues ... también arte, literatura, novelas y hasta tragedias ..." (Citado por Badenberg 1989: 277).

${ }^{24}$ Se declaró ineficaz para desempeñar cargos públicos; según su amigo Carlos Ruiz-Tagle "nunca quiso ser vaca sagrada" y murió con una modesta pensión que el gobierno chileno le otorgó por haber sido Premio Nacional de Literatura en 1984. 
piso en actitud poética. Sus padres declararon que "era la primera víctima de la Mandrágora". (Baciu 1979: 26)

Si bien es cierto que existen los poetas malditos, Teófilo Cid sería su más acabada versión nacional. Porque es el hombre que lo tuvo todo, excelente educación, familia acomodada, dinero; este hombre que fue funcionario diplomático y tuvo fama de elegante, durante años no tuvo donde dormir. Y vagó de bar en bar, acortando la noche, para terminar, al amanecer, sobre un banco de una plaza con su infaltable periódico francés. (Citado por Marta Contreras 1985: 44)

Notar, en los manifiestos o textos teóricos de poesía negra, la forma cómo se constituyen los sujetos y de qué manera organizan sus discursos no demanda un análisis sofisticado, uno de esos que sólo los eruditos saben hacer; basta una lectura atenta, encaminada a dar cuenta de lo más elemental que todo texto ofrece.

En estos ensayos, la interpelación, operación mediante el cual toda ideología transforma a los individuos en sujetos, ${ }^{25}$ sigue el viejo y eficaz modelo de funcionamiento de la ideología cristiana que Althusser resumió a manera de ejemplo. ${ }^{26}$ Opera, exactamente igual que la interpelación cristiana, con dos categorías de sujeto: el absoluto, único, y el común o múltiple. Los sujetos de la poesía negra son sujetos comunes, carecen de autonomía, son voces sin discurso propio. Se han constituido como tales por obra y gracia de otro sujeto absoluto; cumplen su función, se realizan y hablan en nombre de ese otro ${ }^{27}$ que, en este caso, es la Mandrágora: símbolo poético del punto medio en que las contradicciones se anulan y, sobre todo, fuente de poder, amor, riqueza y conocimiento. ${ }^{28}$ Los poetas negros actúan ya sea como sujetos literarios o sociales, a pesar de la libertad absoluta que dicen buscar, bajo el imperio de la Mandrágora: “¿Quién podría hoy afrontar todas las pruebas a las cuales es preciso someterse para tener la mandrágora?¿Quién podría cumplirlas con éxito?" (Gómez-Correa 1940: 3) y deben obedecer sumisamente a su llamado de "masacra tu cuerpo cuando el placer te lo exija; suicídate" (Gómez-Correa 1940: 4). Tal vez, en tal actitud de fidelidad hacia los principios negros, tomados por los mandragoristas en calidad de profecías, se halle también el porqué del plagio del que se

25 'La ideología 'actúa' o 'funciona' de manera tal que 'recluta' sujetos entre los individuos (los recluta a todos), o 'transforma' a los individuos en sujetos (los transforma a todos) por medio de esta operación muy precisa que llamamos la interpelación, la cual puede ser representada según el tipo mismo de la interpelación policial más banal de todos los días: '¡eh, usted alli'” (Althusser 1970: 29).

${ }^{26}$ La ideología cristiana, según Althusser, funciona bajo el siguiente mecanismo: "Me dirijo a ti, individuo humano llamado Pedro ... para decirte que Dios existe y que tú debes rendirle cuentas. Y agrega: es Dios quien se dirige a ti por intermedio de mi voz ... He aquí quien eres: jeres Pedro! He aquí tu origen: ¡has sido creado por Dios de toda eternidad, aunque hayas nacido en 1920 después de Jesucristo! ¡He aquí cual es tu lugar en el mundo! ¡He aquí lo que debes hacer! Mediante lo cual, si observas la ley del amor, lograrás la salvación y formarás parte del Cuerpo Glorioso de Cristo" (Althusser 1970: 33).

${ }^{27}$ No en vano uno de los artículos de Gómez-Correa, publicado en el número 4 de la revista Mandrágora, se titula "Yo hablo desde la Mandrágora".

${ }^{28}$ Véase el punto uno del manifiesto que aparece como apéndice de este artículo. 
acusa al surrealismo chileno, puesto que sus textos no son sino trasunto de un modo de plantear el fenómeno de la creación, viejo y ya moribundo en Europa.

Esta forma de constitución del sujeto determina la presencia de un tipo de discurso: el profético. Es profético el discurso de los manifiestos de poesía negra porque, entre otras cosas, el mensaje no pertenece al sujeto emisor —o en todo caso, se legitima en nombre de otro-y porque, fuera de revelar lo oculto, se remite constantemente al futuro. El discurso como profecía le permite al poeta descubrir la poesía místicamente; el poeta debe ser "tocado por la gracia de la Poesía Negra" para, luego, transformado en poeta-profeta (sujeto), ser el portavoz de esa revelación que anuncia la próxima asunción del arte negro:

Hay, sin embargo, algo de lo que yo no he dudado ni siquiera un solo instante, y es el porvenir que le espera a lo negro. Detrás de esas páginas convulsas que han significado la aparición de la Mandrágora, sé que existen innumerables jóvenes que trabajan en el silencio y que un día gritarán en voz alta gracias a la Poesía Negra. Lo negro invadirá la política, la historia, la ciencia, la filosofia, la sociología, el derecho, la moda, etc., produciéndose los más bellos collages del pensamiento". (Gómez-Correa 1943: 15)

En efecto, los textos teóricos de poesía negra, aunque manifiesten lo contrario, tienen mucho de lo que rechazan y poco de lo que dicen. Lanzaron furibundos ataques verbales al capitalismo y a la religión cristiana, pretendiendo ser los primeros portadores de una revolución que todo lo trastrocara; y negando, desde luego, toda la literatura producida anteriormente a ellos en América. Pero en el fondo no sobrepasaron los puntos de apoyo comunes a las mencionadas ideologias: fe en la fuerza individual y a la vez en un orden superior. El mandragorista se instala en la situación límite, pero a la postre todo resulta un sacrificio personal, en nombre de la mística Hermandad de la Mandrágora, que nada revoluciona y que nada cambia. ¿Cuánto de auténtico hay en el ideario de Mandrágora? La autenticidad no radica en decirlo, sino en serlo: La poética negra dista mucho de ser auténticamente revolucionaria.

\section{Obras Crtadas}

Althusser, Louis. Ideología y aparatos ideológicos de estado. Buenos Aires: Nueva Visión, 1970.

Arenas, Braulio. "Mandrágora, poesía negra", Mandrágora 1. Santiago de Chile, 1938. y otros. El AGC de la Mandrágora. Santiago de Chile: Mandrágora, 1957.

Baciu, Stefan. Antología de la poesía surrealista latinoamericana. México: Joaquín Mortiz, 1974.

Surrealismo latinoamericano. Preguntas y respuestas. Valparaíso: Ediciones Cruz del Sur, 1979.

Badenberg, Nana, Alexander Honold y Susanne Hortsmann. “¿Quién mató a Palomino Molero? Vargas Llosa y la novela policial", Revista de Crítica Literaria Latinoamericana 30. Lima, $2^{\circ}$ semestre, 1989.

Contreras, Marta. "Surrealismo en Chile”, Atenea 452. Concepción, $2^{\circ}$ semestre, 1985. Giardinelli, Mempo. El género negro. México: Universidad Autónoma Metropolitana, 1984. 
Goic, Cedomil. "El surrealismo y la literatura iberoamericana". Revista Chilena de Literatura 8. Santiago de Chile: Universidad de Chile, 1977.

Gómez-Correa, Enrique. "Intervención de la poesía". Mandrágora 1 (1938). "Notas sobre la poesía negra en Chile". Mandrágora 3. Santiago de Chile, 1940. "Testimonios de un poeta negro". Mandrágora. Santiago de Chile, 1943.

Lihn, Enrique. "El surrealismo en Chile". Nueva Atenea 423. Concepción, 1970.

Mandrágora 1 (diciembre 1938); 2 (diciembre 1939); 3 (junio 1940); 4 (julio 1940); 5 (junio 1941); 6 (septiembre 1941) y 7 (octubre 1943). Santiago de Chile.

Lastra, Fernando de la. "Braulio Arenas, humanista y escritor completo". Atenea 457. Concepción: Universidad de Concepción, 1er. semestre, 1988.

Rey, Tomás. "Apuntes sobre el para-surrealismo y el surrealismo en Chile". Zona Franca 11. Caracas, febrero, 1972.

Santana, Francisco. Evolución de la poesía chilena. Santiago: Editorial Nascimiento, 1976.

Vallejo, César. "Autopsia del superrealismo". Amauta 30. Lima, abril-mayo, 1930. "Contra el secreto profesional". Las vanguardias literarias en Hispanoamérica. Roma: Bulzoni Editore, 1986. Estudio y compilación de Hugo Verani.

Wilson, Jason. "Surrealismo en Chile, ¿colonialismo cultural?". Cormorán 8. Santiago de Chile: Editorial Universitaria, 1970.

\section{APÉNDICE}

\section{MANDRÁGORA ${ }^{29}$}

1.- La mandrágora es una planta de la familia de las solanáceas, cuya raíz tiene una curiosa formación humana. Cuando esta raíz es negra tiene la forma de una mujer, y cuando es blanca representa a un hombre. No se le puede arrancar directamente de la tierra, bajo pena de morir inmediatamente. Pero quien logra la posesión de la mandrágora tendrá el poder, el amor, la riqueza y el conocimiento.

2.- Poéticamente, ella representa a la poesía negra, es decir a la poesía cuyo estado se transmite tanto en forma de poemas como en actos revolucionarios. La poesía negra es la organización más fría de la palabra, la dispersión más absoluta del amor, la necesidad más vehemente del placer, el ansia más sedienta del peligro. La poesía negra quiere destruir la valla convencional de los principios del bien y el mal, según la clasificación vigente. Ella presta toda su confianza a la revolución para hacer desaparecer estas fronteras. Pretende conseguirlo aun arrojándose con cuerpo y alma (la mandrágora no cree en el alma) en la investigación y aplicación del principio del mal, único estado que da sentido a la vida de sus propugnadores, aliando a este estado los sobrantes y atributos con los que la actual

\footnotetext{
${ }^{29}$ Este documento es, sin duda alguna, un manifiesto del surrealismo chileno. Lo transcribimos tal y conforme apareció por primera vez en el número 4 de la revista Mandrágora, (Santiago de Chile, julio de 1940: 7).
} 
sociedad capitalista fulmina a sus atacantes, haciendo, por ejemplo, del problema del incesto la mejor oposición al hombre actual que posee una mentalidad de boy-scout. Para la mejor solución de todos los problemas, la mandrágora admite como táctica la violencia física y la violencia moral.

3.- El hecho de poner en contradicción los principios duales del bien y el mal, al admitir que las fuerzas más reaccionarias de la actual sociedad se han refugiado en el bien, nos obliga a atacar este principio, aún a riesgo de recibir censuras más enconadas y aún a riesgo de ampliar indefinidamente nuestro campo de batalla antinómico. Por esa razón, todos los componentes del grupo de la mandrágora, se sienten y actúan siempre bajo el imperativo de la ilegalidad.

4.- Creado bajo el concepto de la lucha minoritaria, nosotros atacamos siempre frente a frente a nuestros enemigos, ya sea por medio de la palabra o de la acción. Nuestras últimas experiencias tienen por objeto demostrar prácticamente que es posible conciliar ambas energías en un solo resultado poético.

5.- En cuanto a los antecedentes que sirvan para la inspiración total del poeta "negro", podemos decir que ellos reposan en las aguas de la memoria, donde fermentan los impulsos anímicos de la inteligencia, del pensamiento y del instinto, aguas que, al agitarse convulsivamente por el placer, se separan en sensaciones aisladas, provocando la ruptura inmediata de su unidad central, para reproducir fragmentariamente los estados caóticos y deliciosos del crimen, del vicio, de la inspiración y el desencanto.

6.- La mandrágora hace suyas todas las manifestaciones del humor negro, en cualquiera de sus formas, ya sea el dandysmo (Jacques Vaché, Jacques Rigaut), la crueldad (Swift), la moral (Sade), el terror (Lautréamont), la descripción (Roussel), etc...y en general hace suyas todas las manifestaciones del surrealismo.

7.- Históricamente la mandrágora salta de los siglos de Dante y Bandello al siglo isabeliano (Ford, Marlowe, Webster y Tourneur) a los tiempos de Anne Radcliffe, Lewis, Walpole, Young y Chatterton, y después a los románticos alemanes (von Arnim, Kleist, Jean-Paul para pasar los de Nerval, Baudelaire, Mallarmé y Rimbaud, para llegar en nuestro siglo a Breton, Éluard, Péret y Apollinaire.

8.- Creemos que la planta de la mandrágora no podría haber fructificado en estas tierras estériles y sin mayores preocupaciones por ninguna cuestión moral, si antes no se hubiera alzado, como el más hábil segador, en una empresa de limpia revolucionaria nuestro amigo Vicente Huidobro. Él ha sido quien ha liberado a la poesía de nuestro idioma de la bajeza, de la retórica y de la prisión, y la ha puesto en su rol de perfeccionamiento y de pureza activa.

9.- Nuestra poesía aspira, ante todo, a ser una voz de protesta, una voz de alarma. Ella está signada por la exageración. Seguramente que hoy por hoy muchas de nuestras experiencias no serán comprendidas. Pero, tarde o temprano, las veremos ser aceptadas plenamente. Nosotros serviremos de punto de unión. Hemos adelantado nuestro destino. Estamos lejos. Corremos en una competencia de caracoles. Hemos incendiado el cielo. Ante la inminencia del peligro, todos deben correr, incluso para despedazarnos. Nosotros queremos fomentar una competencia de centellas. Nuestro optimismo y nuestro pesimismo poético, unidos forman la más bella fisonomía del amor. 